\title{
Effectiveness of an educational intervention on sexual and reproductive health education directed at school teachers in the Kalutara district
}

\author{
R Hettiarachchi ${ }^{1 *}$, S Sivayogan², S A P Gnanissara ${ }^{3}$ \\ 1. Consultant Community Physician, National Institute of Health Sciences, Kalutara. \\ 2. Professor of Community Medicine, Department of Community Medicine, Faculty of Medical Sciences, University of Sri Jayawardanepura. \\ 3. Former DDG [Education, Training \& Research] Ministry of Health.
}

\begin{abstract}
The global trend of early onset of puberty combined with increased age at marriage leading to an increase in premarital sex is also observed in Sri Lanka. In contrast, less priority is given for sexual and reproductive health education in Sri Lankan schools.
\end{abstract}

The objective of this study was to plan, implement and evaluate the effectiveness of an educational intervention on Sexual and Reproductive Health (SRH).

A quasi-experimental study was designed based on a situational analysis of existing SRH education in schools and its effectiveness was evaluated. A four-day teachertraining workshop was carried out for the thirty one teachers in the intervention group. Thirty teachers in the control area were exposed to the pre-existing SRH seminars. After the intervention, teachers in both groups were made to teach SRH lessons to Grade Nine students in their respective schools to measure the impact of the intervention. Sixty-one teachers and 914 students aged 15-16 years completed self-reported pre and post intervention questionnaires on SRH knowledge and attitudes. Scores for pre-post tests of each study group and post-post tests between intervention and control groups were compared. Post intervention teaching skills of teachers in both study groups were also assessed using standard checklists.

Teachers in the intervention group had higher mean scores for post intervention knowledge on pregnancy and related issues [intervention group - 21.9(11.5), control group 19.6(13.0); p-0.02]; and Sexually Transmitted Infections [intervention group - 12.9(9.5), control group - 7.5(4.6); p-0.01]. Mean scores for teaching skills were significantly improved in the intervention group [intervention group -83.0 (20.3), control group-58.8 (33.1); p-0.002]. There was also a significant improvement in SRH knowledge [intervention group - 28.5(13.6), control group - 21.8 (12.9); p-0.02] and attitude [intervention group - 8.4, control group -3.1; $\mathrm{p}-0.017$ ] among students in the intervention group.

Developing and delivering a new educational intervention for SRH education based on situational analysis proved successful with regard to the improvement of SRH teaching skills and knowledge among teachers and students. Thus it is recommended to use this intervention in more settings and to include it into the school curriculum.

\section{INTRODUCTION}

The global trend of early onset of puberty and increased age at marriage, leading to increase in premarital sex is also observed in Sri Lanka where the mean age of menarche is 11.4 and age of marriage is 24.6 years (Ministry of Health, Nutrition and Welfare 2002). The period between menarche and marriage is seen as a risk period for reproductive health of adolescents as they initiate and continue sexual activities (WHO 1999). These factors may lead to sexual abuse, unwanted pregnancies, unsafe abortions, maternal deaths and contracting STIs including HIV/AIDS (WHO 1998).

Even though various Sexual and Reproductive Health

* Corresponding author (hrasanjalee@yahoo.com) 
(SRH) education programmes are carried out in many countries, only a few have evaluated its impact on adolescents' sexual behaviour (WHO 1999; WHO 1998; Ying et al. 2004). Many have feared that it might encourage sexual activity among young people who are not yet sexually active, and increase levels of risk-taking behaviour among those who are sexually experienced (WHO 1999; WHO 1998; Ying et al. 2004; WHO 1997). Discussion points include; how much explicit educational material should there be, how often should sexual education be given and at what age should this education be initiated. (Miller 1992). However, it has been shown that well-designed SRH education programmes can positively influence the delay in initiation of sexual activity, reduce the number of sexual partners and reduce unplanned pregnancy and STIs (Stiernborg et al. 1996; Susan et al. 2000).

Although many interventions were carried out to improve Adolescent Sexual and Reproductive Health (ASRH), there is a lack of an effective school based intervention package in many developing countries including Sri Lanka. Scientific and valid information on effective interventions promoting ASRH would make a positive contribution towards making policy decisions and programme planning for ASRH. By conducting scientific intervention programmes, researchers can identify the effectiveness of the programme as well as deficiencies of the implemented interventions. This will help to determine better ways of conducting new programmes in an effective and sustainable manner by overcoming the deficiencies. Therefore, investment is needed in research to provide practical and sustainable solutions, which will reduce SRH problems among adolescents.

Teaching SRH requires different skills and approaches compared to teaching other less sensitive, more conventional subjects (SIECUS 1998). Teaching the content alone is not sufficient in sexual health education. Students may be able to pass a paper-pencil test on health knowledge, but this does not ensure that the student will put that knowledge into practice. This is known as a "health behaviour gap", which refers to the discrepancy between personal health knowledge and general health behaviour (Reddy 1997).

The Ministry of Education in Sri Lanka introduced Sexual and Reproductive Health (SRH) component into the school curriculum in 1994 and revised it in 1999. During the past ten years, teacher-training programmes for SRH conducted in Sri Lanka have consisted mainly of knowledge-based seminars and were not focused to develop competency in SRH teaching (UNFPA 1998).
In addition, even though SRH had been included in the school curriculum, knowledge of and attitude to SRH was low among Sri Lankan adolescents (UNICEF 2004; Basnayake 2001; National Institute of Education 1993). In an attempt to improve this, a new educational intervention on SRH education was designed for adolescents and assessed the feasibility and evaluated the effect of implementing this in Sri Lankan schools.

\section{METHODOLOGY}

\section{Study site and population:}

This study was carried out in the Kalutara district. The Kalutara district is located in the Western Province of Sri Lanka. It has a population of about one million, of which $20 \%$ are adolescents. For educational purposes Kalutara district is divided into three educational zones, namely Kalutara, Horana and Mathugama (UNFPA 1991). Grade Nine students were considered as the most appropriate group to evaluate the effectiveness of SRH intervention because in Sri Lanka, SRH teaching is already part of the curriculum for Grade Nine students. There are 218 schools with Grade Nine classes in the Kalutara district with 5,488 Grade Nine students (UNFPA 1991). This study was conducted in two comparable educational zones. Kalutara educational zone was selected as the intervention area and Horana educational zone as the control area.

\section{Study design:}

A quasi-experimental, equivalent control group design with pre-test post-test components was used to evaluate the effectiveness of the new SRH educational package. The study consisted of five phases.

\section{Phase I - Situational analysis of existing SRH education}

To identify the existing situation for SRH education, five informal interviews were carried out with experts in both the health and educational sectors in Sri Lanka who had experience in SRH education. Focus group discussions were carried out with school principals, master teachers, health and physical education teachers, Grade Nine school children and their parents. Documents relating to SRH education such as the school curriculum, school text books relating to SRH, Teachers' Guide Books, previous reports on school SRH education and five year work plans on school education were reviewed. The availability of basic facilities in schools such as whether 
there was a separate classroom for Grade Nine students, adequate numbers of desks and chairs, blackboards and teaching-learning aids for SRH education were also assessed using a checklist.

\section{Phase II-Selection of study groups and pre-intervention assessment}

Among 218 schools with Grade Nine classes only sixty one schools had "Health and Physical Education" teachers who teach SRH. All these sixty one schools were included in the study (thirty one schools in intervention area and thirty schools in control area). Sixty one "Health and Physical Education" teachers (one Health and Physical Education teacher from each school) were included as the primary target group in the study.

To evaluate the effectiveness of the intervention, Grade Nine students who are taught SRH lessons by Health and Physical Education teachers in intervention and control groups were included as secondary target group for the study. In calculating the sample size for Grade Nine students, it was considered necessary to identify a difference in the stated outcome of at least $15 \%$ from a baseline value of $35 \%$ with power of $85 \%$. A multi-stage sampling method was adopted. A Grade Nine class was considered as a cluster. Sixty one Grade Nine classes (one class from each school) were randomly selected for the study. To minimize the clustering effect, the obtained value was multiplied by a clustering effect of two (Hulley et al.1991). Accordingly, from the sixty one schools, 914 students (15 from each class) were selected randomly with almost equal numbers of boys and girls (483 girls and 431 boys).

The pre-intervention assessment was carried out in the respective schools one week before the educational intervention was introduced. Two separate self-reported pre-coded and pre-tested questionnaires (one for students and one for teachers) were used to gather information on knowledge and attitudes in relation to SRH. The questionnaire included three sections: (i) Sociodemographic characteristics, (ii) a section evaluating $\mathrm{SRH}$ related knowledge including anatomy and physiology of the reproductive system; and knowledge about pregnancy, abortion, subfertility and STIs and (iii) a section evaluating participants' attitude towards SRH related issues, size of sexual organs, nocturnal emission, masturbation, menstruation, virginity and myths surrounding STIs.

Data collectors were informed about the objectives of the study, random selection of students, and distribution of the questionnaires, problems that can occur during the data collection and how these can be tackled. Guidelines on data collection were prepared and given to the data collectors to facilitate and standardize the data collection.

\section{Phase III - Development of the new SRH educational intervention package}

Information obtained in Phase I and II was analyzed by using the SWOT model [Strengths, Weakness, Opportunities and Threats] (Table 01 in the results section) to understand how various factors affect SRH education and used to design the educational intervention. A trainer's manual on SRH teaching was developed with emphasis on the depth of knowledge a teacher should possess, skills needed to teach sensitive topics, developing a positive attitude towards SRH teaching and a good teacher-student relationship. The Teachers' Guide consisted of a general introduction, model lesson plans with educational objectives, teaching methods and examples of health messages for adolescents. An information sheet with relevant diagrams and simple explanation of the content was included. This guide was developed to be user-friendly.

\section{Phase IV - Introduction of the SRH educational intervention}

Intervention was carried out as a four day teacher training workshop for the teachers in the intervention group. There were six- 45 minutes sessions per-day consisting of lecture discussions supported by visual techniques and participatory learning methods, small group activities, case studies, role-playing exercises, demonstrations and micro-teaching sessions. Topics discussed during the training workshop included: importance of teaching SRH in schools, physical and psychological changes that occur during adolescence, prevention of teenage pregnancy, sexual abuse, unsafe abortions and STIs/AIDS, personal hygiene of reproductive organs, how to dispel myths about e.g. size of sexual organs and discuss topics such as nocturnal emission, masturbation, menstruation and virginity. During the workshop teachers were specially trained to prepare lesson plans for SRH teaching and to talk about sensitive issues openly with adolescents. In the intervention area this workshop replaced the usual annual seminars on SRH as given by the Ministry of Education. Teachers in the control area continued with the annual seminars consisting of non- participatory lectures on anatomy and physiology of the reproductive system (4-days of seminars). 


\section{Phase V - Post intervention assessment}

One month after the training workshops and annual seminars, teachers in both intervention and control groups were asked to teach SRH lessons according to the existing curriculum to Grade Nine school children in their respective schools during the given period of time allocated to this in the curriculum (one and half monthsone classroom session per week).

Teaching skills of all teachers in the intervention group and the control group were assessed by master teachers using a validated checklist. Post intervention knowledge and attitude to SRH among teachers in both study groups were assessed one week after completion of SRH teaching in schools by using the same self-reported questionnaires used in the pre intervention assessment. The impact of the intervention was evaluated from post intervention knowledge of and attitude to SRH among Grade Nine students in the intervention and control areas (one week and six weeks after completion of SRH teaching) by administering the same self-reported questionnaires used in the pre-intervention assessment.

\section{Statistical analysis}

For continuous variables, mean scores on SRH knowledge and teaching skills were calculated and the t-test was used to assess differences between the intervention and control groups. Scores of attitude were not normally distributed. Therefore, non parametric tests i.e. Man Whitney U-test (for unpaired data) and Wilcoxan signs rank test (for paired data) were applied to assess the difference between pre and post intervention attitudes and difference between intervention and control groups. Data were analyzed using SPSS version 12.0.

\section{Ethical approval}

Ethical clearance for this study was obtained from the Ethical Review Committee of the Faculty of Medicine, University of Colombo, Sri Lanka. Written informed consent from the parents or guardians was obtained for all children. Before the study commenced permission was also obtained from the Ministries of Education and Health, and from the Provincial Directors of Education and Health - Western Province, Deputy Provincial Director of Health Services (DPDHS) Kalutara and the school authorities. All data collected at the pre and post intervention assessments were handled maintaining strict confidentiality throughout the study.

\section{RESULTS}

Socio-demographic information of teachers in the intervention and control groups were compared. The majority of teachers were in the 30-39 year age group and there was no significant difference in the mean age of teachers in the intervention (37.1) and control group (34.3) $(\mathrm{p}=0.176)$. The majority of teachers in both groups were female(interventiongroup-74.1\%, controlgroup-80.0\%).

More than $95 \%$ of teachers were Sinhalese (intervention group $96.7 \%$, control group $100.0 \%$ ) and the majority of them were Buddhists (intervention group 96.7\%, control group $90.0 \%$ ). When comparing their educational level only $25.0 \%$ of teachers in the intervention group and $20.0 \%$ in the control group had done the GCE (A/L) examination in science subjects. This difference in educational qualification was not statistically significant $(\mathrm{p}=0.651)$.

The majority of teachers who were given the responsibility of teaching SRH were appointed as Health and Physical Education teachers $(90 \%)$. The mean duration of service was 14 years and duration of teaching Health and Physical Education subject is 10 years in both study groups. Mean number of years experience of teaching SRH was 4.7 (SD 2.6) and 6.2 (SD 3.2) years in the intervention and control group respectively. It is important to note that $80.0 \%$ of teachers in both groups had never received any in-service training in SRH.

There was no statistically significant difference in sociodemographic data (age, sex, ethnicity, religion, parent's education level, parent's occupation) between students in the intervention and control groups.

Information obtained in phase I and II was analyzed and is presented in Table 1 .

\section{Assessment of Teachers}

All 61 teachers were assessed during the post- intervention survey (intervention group - 31 and control group - 30). Table 2 presents the information obtained by assessing the SRH teaching skills of Health and Physical Education teachers in the intervention group and the control group in their respective schools during the given period. 
Table 1 : Strengths, Weaknesses, Opportunities and Threats (SWOT) for SRH education - A situation analysis of SRH Education in Sri Lanka

\begin{tabular}{|c|c|}
\hline Strengths & Weaknesses \\
\hline $\begin{array}{l}\text { 1. Principals, master teachers, teachers, students, parents } \\
\text { and experts in the health and education sectors were all of } \\
\text { the opinion that school is the most appropriate place for } \\
\text { Sexual and Reproductive Health (SRH) education }\end{array}$ & $\begin{array}{l}\text { 1. Lack of teaching-learning materials to teach SRH } \\
\text { 2. SRH information presented in the existing school text book } \\
\text { was not explained properly and difficult to understand for } \\
\text { a non-medical person }\end{array}$ \\
\hline $\begin{array}{l}\text { 2. Students are interested and curious to learn about SRH } \\
\text { issues }\end{array}$ & $\begin{array}{l}\text { 3. Existing teacher-training programmes on SRH were not } \\
\text { focused on teaching methodology and skills }\end{array}$ \\
\hline $\begin{array}{l}\text { 3. Students like to learn SRH issues from teachers who } \\
\text { develop good teacher-student relationship and have good } \\
\text { knowledge }\end{array}$ & $\begin{array}{l}\text { 4. Existing teacher-training programmes on SRH were not } \\
\text { designed based on assessment of what teachers feel they } \\
\text { need }\end{array}$ \\
\hline $\begin{array}{l}\text { 4. An SRH component was already included in the school } \\
\text { curriculum }\end{array}$ & $\begin{array}{l}\text { 5. Health and Physical Education teachers' attitudes towards } \\
\text { SRH education was not positive }\end{array}$ \\
\hline $\begin{array}{l}\text { 5. Teachers were aware that they did not have adequate skills } \\
\text { to teach SRH }\end{array}$ & $\begin{array}{l}\text { 6. Grade Nine school children's knowledge of and attitudes } \\
\text { to SRH was poor }\end{array}$ \\
\hline $\begin{array}{l}\text { 6. Higher officials in health and education sectors had already } \\
\text { identified the importance of training teachers to develop } \\
\text { competency in SRH teaching }\end{array}$ & \\
\hline $\begin{array}{l}\text { 7. Health and Physical Education teachers had satisfactory } \\
\text { knowledge on SRH in the pre-intervention assessment }\end{array}$ & \\
\hline
\end{tabular}

\section{Opportunities}

1. Several funding bodies (UNFPA, UNICEF, Plan) in Sri Lanka were keen to promote adolescent reproductive health education and funds are available for SRH education

2. Most of the parents preferred to give the school responsibility for SRH education

3. Annual seminars on SRH for Health and Physical Education teachers were conducted by the Ministry of Education regularly

\section{Threats}

1. In Sri Lankan culture SRH issues are not discussed openly

2. There is an inadequate number of teachers to teach the Health and Physical Education" subject

3. The time allocated in the school curriculum to teach SRH was not enough

4. The SRH lessons in the Grade Nine curriculum and text book are last lessons, therefore sometime not taught due to time constraints in delivering the whole curriculum

5. According to teachers and parents the media give misleading messages about SRH

6. Majority of parents do not like to discuss SRH issues with their children

7. Some parents did not understand and appreciate the importance of SRH education 
Table 2 : Comparison of mean scores of teaching skills on Sexual and Reproductive Health teaching of Health and Physical Education (H\&PE) teachers: Post intervention

\begin{tabular}{|l|c|c|c|}
\hline \multicolumn{1}{|c|}{ Supervisory Variables } & $\begin{array}{c}\text { Intervention group (n=31) } \\
\text { \% Mean score } \\
\text { (SD) }\end{array}$ & $\begin{array}{c}\text { Control group (n=30) } \\
\text { \% Mean score } \\
\text { (SD) }\end{array}$ & P -Value \\
\hline 1. Clarity and relevance of lesson & $97.5(7.5)$ & $71.6(39.2)$ & 0.001 \\
objectives & $96.7(17.9)$ & $80.0(38.5)$ & 0.036 \\
2. Initiation of the session & $91.3(27.1)$ & $82.2(35.8)$ & 0.266 \\
3. Lesson planning & $91.9(13.5)$ & $75.0(38.8)$ & 0.030 \\
4. Coverage of subject content & $88.0(26.3)$ & $63.3(39.2)$ & 0.006 \\
5. Session presentation & $59.6(47.2)$ & $61.6(48.5)$ & 0.872 \\
6. Teaching/learning materials used & $93.5(24.9)$ & $73.3(44.9)$ & 0.036 \\
7. Teaching methods & $88.7(24.8)$ & $36.7(49.8)$ & 0.247 \\
8. Method of evaluation & $51.5(50.7)$ & $75.5(36.5)$ & 0.031 \\
9. Time allocation & $91.9(17.1)$ & $78.5(38.3)$ & 0.023 \\
10. Teacher- student relationship & $96.7(17.9)$ & $65.0(43.8)$ & 0.001 \\
11. Management of the class & $98.3(8.9)$ & $\mathbf{5 8 . 8 ( 3 3 . 1 )}$ & $\mathbf{0 . 0 0 2}$ \\
12. Ending of the lesson & $\mathbf{8 3 . 0 ( 2 0 . 3 )}$ & & \\
\hline Total \% mean score (SD) & & & \\
\hline
\end{tabular}

The difference in teaching skills between two groups was tested using a t-test for independent groups. Statistically significant higher mean scores were obtained in the intervention group compared to the control group for most of the components of the checklist (Table 2).
Table 3 presents the summary of the pre and post intervention assessment results on SRH knowledge, attitudes and teaching skills of Health and Physical Education teachers and SRH knowledge and attitudes of Grade Nine school children in the intervention and

Table 3 : Pre and post intervention assessment results on SRH Health and Physical Education teachers and knowledge and attitudes of Grade Nine school children

\begin{tabular}{|c|c|c|c|c|}
\hline Character & \multicolumn{2}{|c|}{ "Health and Physical Education" teachers } & \multicolumn{2}{|c|}{ Grade nine school children } \\
\hline \multicolumn{5}{|l|}{ Knowledge on Sexual and Reprodetive Health } \\
\hline & $\begin{array}{l}\text { Mean Score } \\
\text { (SD) }\end{array}$ & $\begin{array}{l}\text { Singnificance } \\
\text { (p value) }\end{array}$ & $\begin{array}{l}\text { Mean score } \\
\text { (SD) }\end{array}$ & $\begin{array}{l}\text { Significance } \\
\text { (p value) }\end{array}$ \\
\hline Pre-post-Intervention group & $\begin{array}{lr}17.8 & -20.0 \\
(9.5) & (9.1)\end{array}$ & $\begin{array}{l}-0.3674 \\
(0.7946)\end{array}$ & $\begin{array}{lr}14.6-26.5 \\
(12.2) \quad(13.6)\end{array}$ & $\begin{array}{c}-9.768 \\
(0.0001)\end{array}$ \\
\hline Pre-post - Control group & $\begin{array}{lr}18.5 & -19.4 \\
(12.0) & (12.3)\end{array}$ & $\begin{array}{l}-0.1515 \\
(0.8901)\end{array}$ & $\begin{array}{lr}15.6 & -21.8 \\
(13.2) & (12.9)\end{array}$ & $\begin{array}{c}-1.829 \\
(0.0997)\end{array}$ \\
\hline Post-post - Intervention and Control groups & $\begin{array}{lr}20.0 & -19.4 \\
(9.1) & (12.3)\end{array}$ & $\begin{array}{c}1.3680 \\
(0.0915)\end{array}$ & $\begin{array}{lr}28.5 & -21.8 \\
(13.6) & (12.9)\end{array}$ & $\begin{array}{l}-9.876 \\
(0.0000)\end{array}$ \\
\hline \multicolumn{5}{|c|}{ Attitudes towards Sexual and Reproductive Health } \\
\hline Pre-post - Intervention group & $14.3-31.0$ & $\begin{array}{c}2.065 \\
(0.013)\end{array}$ & $4.7-8.4$ & $\begin{array}{l}3.987 \\
(0.029)\end{array}$ \\
\hline Pre-post - Control group & $9.7-30.1$ & $\begin{array}{l}4.768 \\
(0.001)\end{array}$ & $2.0-3.1$ & $\begin{array}{c}0.998 \\
(0.450)\end{array}$ \\
\hline $\begin{array}{c}\text { Post-post - Intervention and } \\
\text { Control groups }\end{array}$ & $31.0-30.1$ & $\begin{array}{l}0.907 \\
(>0.05)\end{array}$ & $8.4-3.1$ & $\begin{array}{c}2.3 \\
(0.017)\end{array}$ \\
\hline \multicolumn{5}{|c|}{ Teaching skills of Health and Physical Education teachers } \\
\hline & \multicolumn{2}{|c|}{ Mean score (SD) } & \multicolumn{2}{|c|}{ Significance (p value) } \\
\hline Post - Intervention group & \multicolumn{2}{|c|}{$83.0(20.3)$} & \multirow{2}{*}{\multicolumn{2}{|c|}{$3.266(0.002)$}} \\
\hline Post - Control group & \multicolumn{2}{|c|}{$58.8(33.1)$} & & \\
\hline
\end{tabular}


The difference in pre and post intervention knowledge among teachers in the intervention group was compared to that of those in the control group. Significance of difference was tested by using a paired t-test. There was a statistically significant improvement in knowledge of the section on pregnancy related issues (conception, pregnancy, abortion and sub fertility) (p-0.001) and sexually transmitted infections (P-0.001) in the intervention group, with no statistically significant improvement in the control group ( $>0.5)$. However, when comparing the difference in mean scores for overall (all sections) knowledge of SRH, teachers in neither the intervention nor the control group demonstrated a statistically significant improvement in knowledge ( $\mathrm{p}$ $0.79, \mathrm{p} 0.89$ ) (Table 3).

Significance of difference in pre and post intervention attitude to SRH among teachers was tested using the Wilcoxan signs rank test. There was a statistically significant increase in mean scores for attitude for all the selected subtopics of SRH (all sections) among teachers in both intervention and control groups ( $\mathrm{p} 0.001, \mathrm{p} 0.01$ ) (Table 3).

\section{Assessment of students}

For students, significance of difference in pre and post intervention knowledge was tested using the $t$ - test for independent samples. For the first post-intervention tests (after one week), a statistically significant improvement in mean score for knowledge on anatomy and physiology of reproductive systems (p 0.0001); pregnancy related issues (p 0.01); and Sexually Transmitted Infections ( $p$ 0.01 ) was noted in the intervention group. In the control group there was no statistically significant improvement $(\mathrm{P}>0.05)$. With regard to attitude there was a statistically significant improvement in attitude to SRH in the intervention group on most of the selected subtopics reflected in the difference in mean overall score $(\mathrm{p}$ 0.029) (Table 3). In the control group a statistically significant difference was noted in a negative direction (less good attitude score) for some of the topics such as masturbation (mean score: pre-test: -2.1 ; post-test: -5.2 ) and size of sexual organs (mean score: pre-test: -4.7 ; post- test: -6.5). A statistically significant improvement in mean scores for knowledge on anatomy and physiology of reproductive system; pregnancy and related issues; and sexually transmitted infections was exhibited in both intervention and control groups $(\mathrm{p}<0.01)$ in post test 2 (six weeks later). However, there was no statistically significant improvement in SRH attitude in post test 2.

\section{DISCUSSION}

The results of the Focus Group Discussions (FGDs) and informal interviews revealed the importance of SRH education in schools and the school was identified as the most appropriate place to educate children on Sexual and Reproductive Health. However, officials in the education sector did not have a clear idea on age appropriate SRH education and the current needs of adolescents. Moreover, school children and their parents expect good SRH education to be established in schools. Furthermore, factors affecting SRH education and training needs of teachers were identified during the situational analysis of existing SRH education in schools. This revealed that although the importance of giving SRH education in schools was agreed upon by experts in both the health and educational sectors, as well as by most parents, the existing training in teaching SRH to adolescents for teachers was not based on a needs assessment and was not directed to improving teaching skills to enable teachers to address sensitive issues with confidence. Lack of competency in teaching sensitive issues is a common problem faced by teachers during SRH teaching sessions (Awasthi 2000). Another main barrier for successful SRH teaching that was identified in this study was the inadequacy and lack of appropriate teaching/learning materials. Therefore, it was agreed that there was an urgent need to prepare a user friendly teachers' guide on SRH teaching at least to cover the existing curriculum. In this study, teachers in the intervention group obtained statistically significant higher mean scores for SRH teaching skills than those in the control group, showing improved competency after participating in the new training workshops. Teachers' knowledge of some specific areas (about pregnancy related issues) was improved after the intervention although total mean score of knowledge did not show any significant improvement. However, there was a statistically significant improvement in knowledge of and attitude to SRH among students in the intervention group after introducing the new SRH educational package (with no statistically significant improvement in the control group). It is recommended that SRH teaching skills are assessed in an actual classroom setting rather than in micro-teaching sessions (Abbatt 1992). Hence, teaching skills were assessed only after the intervention, while carrying out teaching sessions in the classroom. Master teachers in Health and Physical Education assessed the teaching skills of the teachers in both study groups during their normal supervisory visits. All the teachers who were selected for the study were informed that this would happen. 
This may have led to bias as they may have performed better than during normal (unsupervised) classroom sessions (Hawthorne effect). However, teachers in the intervention group clearly exhibited a better performance in SRH teaching than in the control group (p-0.002).

We have shown that the new educational intervention can improve adolescents' knowledge of the anatomy and physiology of male and female reproductive systems; pregnancy and related issues; and sexually transmitted infections. A non-randomized controlled trial used to evaluate an AIDS Education Programme among Grade Ten students in two public schools in Oklahoma city also showed significant improvement in knowledge among students (Huszti et al. 1999). This shows that the effective SRH educational interventions improve the participants' SRH knowledge.

Attitudes towards SRH among adolescents in the intervention group became more positive (mean scores: pre 4.7 post 8.4 ). An intervention on AIDS education for primary school children in Tanzania also revealed that pupils in the intervention group scored significantly higher marks for the knowledge, attitude and communication skills $(\mathrm{P}<0.001)$ related to AIDS (Klepp et al. 1994). Another study done in Nigerian secondary school students revealed that students can benefit from specific education programmes that transmit important information necessary to prevent risky behaviour, and improve knowledge and attitude towards HIV/AIDS (Fawole et al. 1999). Similar studies conducted to evaluate the effectiveness of reproductive health related interventions have shown a positive influence on knowledge, attitudes and behaviour in relation to reproductive health (Fawole et al. 1999; Agha et al. 2004; Cha-Hua 2004). The present study further observed that attitudes toward masturbation and size of sexual organs changed in a negative direction (less positive) among adolescents in the control group. This highlights the fact that SRH education because of its sensitive nature, if not handled carefully and if accurate knowledge is not transmitted, may result in a deterioration of existing status. It clearly showed that sensitive issues in SRH should be taught by well qualified trained teachers. We recommended collaboration between the education and health sectors to determine the content of the SRH curriculum and incorporation of a learnercentered educational package such as the one used in this study, which is low in cost and has the advantage of a participatory approach. Training of teachers alone is not adequate to improve health education in schools (Gilbert 1987). Supervision of the performance of SRH teaching by master teachers, providing relevant teaching/learning materials, allocation of adequate time for SRH teaching, sensitizing principals of the schools on the importance of SRH teaching should all be considered when introducing a comprehensive new SRH education package. This study was carried out in one district of the country and the results may not be applicable to the other settings. In addition due to the limited resources and time constraints the present study was not able to enhance the validity of the quantitative data by complementing these with qualitative data (e.g. FGDs) to evaluate the effectiveness of the educational intervention on behaviour and attitude in more depth and/or in the longer term. However, we feel this educational package was welcomed by both teachers and adolescents, was easy to use and could be scaled up for use in similar settings.

\section{ACKNOWLEDGEMENTS}

This research was supported by the National Science Foundation, Sri Lanka (Grant No. RG/2004/SE/01). We would especially like to thank all the data collectors, participants and school principals in the study areas for their support and cooperation. We thank the Director and Deputy Directors of the National Institute of Health Sciences- Kalutara, and Divisional Directors of Education in Kalutara district for their support in project implementation.

\section{References}

1. Abbatt, F.R., 1992. Teaching for better learning. 2nd ed. Geneva: World Health Organization.

2. Agha, S. \& Rossem, R.V., 2004. Impact of a schoolbased peer sexual health intervention on normative beliefs, risk perceptions, and sexual behaviour of Zambian adolescents. Journal of Adolescent Health, 34, pp. 441-452.

3. Awasthi, S., Nichter, M. \& Pande, V.K., 2000. School based interventions, developing an interactive STDprevention programme for youth. Studies in Family Planning, 31, p. 138.

4. Basnayake, S., 2001. Reproductive and sexual health education: A Sri Lankan experience. Planned Parent Challenges, 2, pp. 43-45.

5. Chao-Hua, L., Wang, B.O., Shen, Y. \& Er-Sheng G., 2004. Effects of a community based sex education and reproductive health program on contraceptive use of unmarried youths in Shanghai. Journal of 
Adolescent Health, 34, pp.433-440.

6. Fawole, I.O., et al., 1999. A school-based AIDS education programme for secondary school students in Nigeria: a review of effectiveness. Journal of Health Education Research, 14(5), pp. 675-683.

7. Gilbert, J.J., 1987. Educational handbook for health personnel. 6th ed. Geneva: World Health Organization.

8. Hulley, S.B. \& Cummings, S.R., 1991. In Designing clinical research: An epidemiological approach. London: Williams and Wilkins.

9. Huszti, H.C., Clopton, J.R. \& Mason, P.J., 1999. AIDS educational programmes: Effects on adolescents' knowledge and attitudes. Pediatrics, 84 (6), pp. 986-994.

10. Klepp, K.I., et al., 1994. AIDS education for primary school children in Tanzania: an evaluation study. AIDS, 8(8), pp. 1157-62.

11. Merson, M.H., Dayton, J.M. \& O'Reilly, K., 2000. Effectiveness of HIV prevention interventions in developing countries. AIDS, 14, pp. 68-84.

12. Miller, J., 1992. Sexual health education in Asia and Africa. Partnership for sexual health education. Chicago: Meta Press.

13. Ministry of Health, 2002. Nutrition and Welfare. Fifth Asian and Pacific Population Conference. Sri Lanka Country Report. Bangkok, Thailand.

14. National Institute of Education, 1993. A study on knowledge, attitudes and practices of secondary school children in Sri Lanka. A collaborative study of the UNFPA and the National Institute of Education. Sri Lanka: Population and family life education project.

15. Reddy, R.S., 1997. The role of the teacher in health instruction. Teaching health and nutrition. New Delhi :Ajay Verma for Commonwealth publishers.
16. SIECUS. 1998. Sexuality education curricula. SIECUS Annotated bibliographies, 26(6), pp. 1336.

17. Stiernborg, M., Zaldivar, S.B. \& Santiago, E.G., 1996. Effect of didactic teaching and experimental learning on nursing student's AIDS-related knowledge and attitudes. Journal of AIDS-Care, 8(5), pp. 601-608.

18. Susan, A., et al. 2000. Monitoring and evaluating adolescent reproductive health programs. Focus on young adults. Tool series 5. Washington: Agency for international development.

19. UNFPA. 1998. Reproductive health education in schools. Reproductive health program in Sri Lanka. UNFPA.

20. UNFPA. 2001. Terminal survey report on knowledge, attitudes and practices of secondary schools students in Sri Lanka on reproductive health education and reproductive health issues. Population and family life education project.

21. UNICEF. 2004. A National survey on emerging issues among Adolescents in Sri Lanka. Colombo: UNICEF.

22. World Health Organization. 1998. Adolescent health development programmes The Adolescent. The Second Decade, Improving Adolescent Health and Development. Geneva: WHO.

23. World Health Organization. 1999.Programming for adolescent health and development. WHO Technical Report Series. No. 886. Geneva: WHO.

24. World Health Organization. 1997. Sexual behaviour of young people. Progress in human reproductive research. No. 41. Geneva: WHO.

25. Ying, L., et al. 2004. Needs and preferences regarding sex education among Chinese college students: A preliminary study. International Family Planning Perspectives, 30(3), pp. 128-133. 